mortality. The research related to neonatal health in different programmes shows that a post- delivery visit within 3 days by the health workers linked with strong supervision and monitoring system is the most important factor for reducing neonatal mortality. Thus, the programme design needs to focus on the quality monitoring and supervision system as well as improvement in the awareness activities among the community to ensure the target of reducing neonatal moratlity.

\section{RW1-2.4 IMPROVING NEONATAL HEALTH IN THAILAND}

doi:10.1136/jech.2011.142976b.95

S Tripathi.* National Institute for Child and Family Development, Mahidol University, Thailand

The neonatal mortality rate in the country has shown a rapid decline from 14.8 per 1000 in 1990 to 6.5 per 1000 in 2010. This has been possible through various projects implemented from time to time which include 10 Steps for Breastfeeding; Mother and babyfriendly Hospital; Action for Safe Motherhood Program; Thalassaemia Prevention and Control project; Reduction of birth asphyxia project; Prevention of mother to child transmission of HIV/AIDS; the Nutrition and Development Corner and Healthy Daycare Center Project.

Approximately $97.9 \%$ of all births in Thailand take place in a hospital or institution, and are assisted by professionally trained health personnel (doctors/ nurses/midwives). If the birth occurs at home assisted by others, that is, village health volunteer, traditional birth attendant, the midwife or a doctor or nurse would make a follow-up visit to check on the health of the woman and the baby. The $\mathrm{MCH}$ services system at community level is complemented by the hospital component, made up of a network of community hospitals at district level, provincial, regional hospitals, $\mathrm{MCH}$ hospitals, and university hospitals. All levels are linked together by an established referral system. All pregnant women are given the $\mathrm{MCH}$ Booklet and Pregnancy Pathway at the first antenatal visit. The new universal health insurance policy of government since 2002 in a form of capitation payment system guarantees healthcare for all.

\section{RW1-2.5 IMPROVING NEONATAL HEALTH IN SOUTH-EAST ASIA REGION: CURRENT STATUS}

doi:10.1136/jech.2011.142976b.96

\author{
1,2V K Srivastava. ${ }^{1}$ King George's Medical University, Lucknow, India; ${ }^{2}$ Regioinal \\ Councillor, IEA-SEA Region
}

The countries of the Region have $25 \%$ of the global population and more than $40 \%$ of neonatal deaths. After a steady decline in infant mortality rate, there is stagnation attributable to continued high neonatal mortality rates. In several countries, neonatal mortality is about two-thirds of infant mortality. In the hospitals, prematurity tops the cause of deaths while in the community, infections lead the list of causes. The incidence of LBW is high in the countries of the Region varying between $7 \%$ in Thailand to $50 \%$ in Bangladesh. Implementation of simple interventions with proven effectiveness on neonatal outcomes needs to be accelerated at the country level. In addition there is a need to identify the most cost -effective interventions to manage the neonates at first level health facilities and referral institutions and promote their implementa- tion. The Millennium Development Goals (2015) of reducing under five and infant mortality rates cannot be realised unless neonatal mortality declines by about $50 \%$ of the current levels. The neonatal mortality is quite amenable to reduction, since evidence-based, affordable and effective interventions are available to improve neonatal health and reduce neonatal mortality. The recommendations of the symposium would help the counties of the region in scaling up of successful programmes and also modifying the ongoing programmes.

\section{Western Pacific Regional Workshop RW1-3 USING NATIONAL STATISTICAL DATA IN EPIDEMIOLOGIC RESEARCHES}

doi:10.1136/jech.2011.142976b.97

Y Nakamura.* Jichi Medical University, Shimotsuke, Tochigi, Japan

Many of epidemiologic researches are based on individual health data, and epidemiologists get them for the researches directly from participants of the researches. This is the orthodox way to conduct an epidemiologic research, but some epidemiologists get individual information using national statistical data, such as vital statistics. For example, in a cohort study of which endpoints are death, it is easier and the validity is higher if an epidemiologist uses vital statistics rather than the epidemiologist makes efforts to get fetal information from individual participants. In Japan, Annual Comprehensive Survey of Living Conditions includes data concerning health every 3 years so that if an epidemiologist could link the data and vital statistics individually, an cohort study would be constructed with a large and nationwide random sample.

The condition to use the national statistical data differs among countries and areas. For example, the National Death Index system is available in Korea so that cohort studies with fetal endpoints are easier to be conducted than in countries without the system. Although it has become easier to use national statistical data in Japan nowadays than in the past because of a partial amendment of the Statistical Act, epidemiologists in Japan have to make more effort to use the data than in other countries.

In the workshop, epidemiologists in the Western Pacific regions, such as Korea, China, Australia, New Zealand, and Japan, present their situation, and how to make it easier to use the national statistical data for research.

\section{Sub Saharan African Regional Workshop Chair: Dr Cesar Victora RW1-5 IEA REGIONAL WORKSHOP FOR SUB SAHARAN AFRICA}

doi:10.1136/jech.2011.142976b.97a

${ }^{1,2} \mathrm{~J} \mathrm{Nachega*}{ }^{3}{ }^{3}$ Newton Kumwenda*, ${ }^{4} \mathrm{~K}$ Akinroye* ${ }^{1}$ Department of Medicine in Stellenbosch University, Cape Town, South Africa; ${ }^{2} J o h n s$ Hopkins Bloomberg School of Public Health in Baltimore, Maryland, USA; ${ }^{3}$ Johns Hopkins Centre for Global Health Maryland, USA, IEA; ${ }^{4}$ African Heart Network, Africa

Objectives will include taking stock of the current status of epidemiology in the region, discussing the main challenges faced by local epidemiologists and how to strengthen IEA presence in the region. 